\title{
IMPLEMENTASI PROGRAM TAHFIDZ AL-QUR'AN (STUDI KASUS DI SMP UNGGULAN AL-FURQON DRIYOREJO GRESIK)
}

\section{Umi Intiha'ul Habibah}

Universitas Hasyim Asy'ari Tebuireng, Jombang, Indonesia

Email: Umicchabibah02@gmail.com

\begin{tabular}{|c|c|}
\hline INFO ARTIKEL & ABSTRACT \\
\hline $\begin{array}{l}\text { Diterima } \\
5 \text { April } 2021 \\
\text { Direvisi } \\
\text { 10 April } 2021 \\
\text { Disetujui } \\
\text { 15 April } 2021 \\
\end{array}$ & $\begin{array}{l}\text { Islam in the view of Muslims is a savior religion that will } \\
\text { lead people to a better direction, one of the features of } \\
\text { Islam is the Al-Quran. Miracles from the Qur'an are a } \\
\text { guide and differentiator from the previous books. Even } \\
\text { though the miracle of the Koran was revealed in Arabic, } \\
\text { evervone who is prepared to read memorize and }\end{array}$ \\
\hline $\begin{array}{lr}\text { Keywords: } & \\
\text { Islam; } & \text { instructions; } \\
\text { miracles; } & \text { halaqoh; } \\
\text { talaqqi; } & \text { murojaah; al- } \\
\text { quran } & \end{array}$ & $\begin{array}{l}\text { understand the Koran will be able to memorize the } \\
\text { the right method, some of these methods include the } \\
\text { Classical System of Chanting for six days a week. Santri } \\
\text { participate in teaching and learning activities in the } \\
\text { classroom with the National Education curriculum (K } \\
\text { 13) for general subject matter and material for Diniyah } \\
\text { lessons in the pondok curriculum. Talaq system (how to } \\
\text { teach Al-Qur'an. Implemented in learning Tahfidz Al- } \\
\text { Qur'an in this system the students are divided into } \\
\text { halaqoh-halaqoh tahfidz. The material of talaqi includes } \\
\text { ziadah and murojaah. Which research force by doing the } \\
\text { kuanlitatif. The purpose of this research is for the } \\
\text { implementation program of syur tahfidz Al-qur'an (case } \\
\text { study at al-furqon Driyorejo Gresikjunior high school) }\end{array}$ \\
\hline
\end{tabular}

\begin{abstract}
ABSTRAK
Agama Islam dalam pandangan umat muslim adalah agama penyelamat yang akan menuntun manusia ke arah yang sempurna, salah satu keistimewaan agama Islam adalah Al-Qur'an. Mukjizat dari Al-Qur'an adalah petunjuk dan pembeda dari kitab kitab terdahulu. Keajaiban dari al-quran meskipun diturunkan mengunakan bahasa Arab, semua orang yang bersuguhsuguh membaca, menghafal dan memahami Al-Qur'an maka mereka akan mampu menghafalkan Al-Qur'an. Menghafalkan ayat suci Al-Qur'an memerlukan metode yang tepat, beberapa metode tersebut antara lain sistem sistem klasik yang dilakukan enam perteman dalam satu
\end{abstract}




\begin{tabular}{ll}
\hline & minggu. Selain itu, para santri melaksanakan \\
& pembelajaran dengan mengunakan kurikulum dari dinas \\
& pendidikan yang dikenal dengan kurikulum K 13. Sistem \\
& Talaq (cara belajar mengajar Al-Qur'an) dilakukan \\
& dengan membagi siswa kedalam beberapa kelompok \\
Kata kunci: & kelompok atau halaqoh dengan materi talaqoi berupa \\
agama Islam; petunjuk; & ziadah. Metode penelitian yang digunakan adalah dengan \\
mukjizat; halaqoh; talaqi; & melakukan pendekatan kuanlitatif. Tujuan dari penelitian \\
murojaah; al-quran & ini adalah untuk mengetahui implementasi program \\
& tahfidz Al-qur'an (studi kasus di SMP unggulan Al- \\
& furqon Driyorejo Gresik) \\
\hline
\end{tabular}

\section{Pendahuluan}

Bagi semua umat Islam yang memeluk ajaran dari nabi Muhammad SAW, pasti dalam kehidupanya akan menjadikan Al-Qur'an sebagai landasan kehidupan yang ideal. Karena Al-Qur'an merupakan petunjuk kehidupan bagi umat Islam (Subandi \& Chairani, 2010).

Kitab suci Al-Qur'an 15 abad yang lalu sudah memberikan peringatan dan juga ancaman bagi semua manusia yang tidak melaksanakan apa yang ada dalam kitab tersebut. Faktanya, tidak ada yang mampu menandingi Al-Qur'an. Pada turunnya AlQur'an, para pujangga dan ahli sastra Arab sangat banyak. Mereka sangat ahli dalam bidang balaqhah. Demikian juga di era kejayaan ilmu pengetahuan yang bahasa Arab sangat berkembang, tidak satu pun yang ahli diantara mereka yang mampu menyamai kalian dalam Al-Quran. Hal ini menunjukkan bahwa Al-Qur'an adalah mukjizat dan bukti kebenaran (Paridi, 2019).

Allah sangat murah hati kepada semua umat manusia yang ada di dunia sehingga Allah mengutus para Rosul untuk membawa ajaran kitab suci kepada manusia agar sebagai petunjuk dan kabar gembira sebagaimana dalam firman Nya.

"Rasul-rasul pembawa berita gembira dan pemberi peringatan agar tidak ada hujjah (alasan) bagi manusia untuk membantah Allah sesudah rasul-rasul itu diutus". (QS.An-Nisa':165)

Perkembangan Zaman yang semakin lama semakin kompleks membuat manusia harus mampu memecahkan berbagai maca masalah yang terjadi disekitarnya. Sehingga Rosul di utus oleh Allah dengan wahyu untuk membimbing manusia dari zaman kebodohan ke zaman yang benar sesuai dengan Al- Quran dan As-Sunnah rosul (Mu'ammar, 2019).

Di antara keajaiban Al-Qur'an dibaca dengan bahasa aslinya yaitu bahasa Arab oleh seluruh manusia dari bangsa dan ras yang berbeda-beda. Mereka bahkan menghafalnya walau belum memahami atau mengerti arti ayat dan surah yang dihafal. Kekaguman orang Arab muncul ketika mereka melihat orang yang tidak berbicara bahasa Arab memiliki hafalan Al-Qur'an yang baik dan kuat (Rajak, 2017). Mereka bertanya-tanya bagaimana mungkin orang yang tidak bisa berbicara bahasa Arab mampu menghafal seluruh Al-Qur'an? inilah keajaiban Al-Qur'an yang tidak pernah 
pilih kasih kepada golongan dan bangsa tertentu. Walaupun Al-Qur'an diturunkan dengan bahasa Arab, namun Allah menjamin kemudahan untuk mengingat Al-Qur'an sesuai dengan firman-Nya:

“Sungguh kami telah mudahkan Al-Qur'an untuk diingat, apakah ada orang yang mengingat?"

Tidak ada keraguan bahwa membaca dan menghafal Al-Qur'an memiliki banyak keutamaan, seperti yang termaktub dalam Al-Qur'an dan Hadits. Membaca satu huruf dalam Al-Qur'an akan di ganjar dengan sepuluh kebaikan. Jika membaca per huruf saja diganjar dengan banyak kebaikan, membaca dan menghafal seluruh Al-Qur'an tentu memiliki lebih banyak kebaikan dan keutamaan.

\section{Metode Penelitian}

Berdasarkan konteks penelitian di atas maka secara garis besar dapat fokus penelitian ini sebagai berikut

Agar penelitian dapat lebih terarah, maka peneliti membatasi pemahaman dan perbedaan penafsiran yang berkaitan dengan istilah-istilah. Sesuai dengan penelitian yaitu implementasi program tahfidz di SMP Unggulan Al-Furqon Driyorejo Gresik.

Kata dan istilah yang perlu ditulis oleh penulis yaitu:

1. Implementasi

Menurut Daniel A. Mazmania dan Paul Sabatier (1979) dalam (Idhan et al., 2019) mengatakan bahwa:

“ Implementasi adalah memahami peristiwa yang terjadi secara nyata dan dapat dijelaskan dengan teori dan rumusan-rumusan". Implementasi secara sederhana diartikan pelaksanaan atau penerapan.

2. Program

Adalah perlakuan yang berhubungan dengan pelaksanaan dan fungsi dari lembaga dengan artian doktrin yang dilakukan oleh lembaga secara masif untuk tercapainya harapan dan keterselesaian permasalahan.

3. Tahfidz

Adalah menghafal, menurut Abdul Aziz Abdul Ra'uf definisi menghafal adalah "proses pengulanagan yang dilakukan secara terus menerus secara aktif baik dengan mendengarkan ataupun membaca". Pekerjaan apapun jika sering diulang pasti menjadi hafal.

4. Al-Qur'an

Qara'a mempunyai arti mengumpulkan dan menghimpun, dan qira'ah berarti menghimpun huruf-huruf dan kata-kata satu dengan yang lain dalam satu ucapan yang tersusun rapih (Mudzakir, 2013).

Pendekatan yang digunakan dalam penelitian ini adalah pendekatan kualitatif. Penelitian yang lebih menekankan analisisnya pada proses penyimpulan deduktif dan induktif serta pada analisis terhadap dinamika hubungan antara fenomena yang diamati dengan menggunakan logika ilmiah (Nugrahani \& Hum, 2014) 
Penelitian kualtitatif memiliki karakteristik alami sebagai sumber data langsung, dekriptif, proses lebih dipentingkan dari pada hasil. Dalam hal ini jenis penelitian yang digunakan adalah studi kasus tentang impementasi program tahfidz di SMPU Al-Furqon Driyorejo Gresik (Depiyanti, 2014).

Di dalam penelitian kualitatif yang menjadi instrumen adalah peneliti itu sendiri. Oleh karena itu, peneliti sebagai intrumen dituntut untuk memahami seberapa jauh peneliti kualitatif siap melakukan penelitian ke lapangan. Validasi terhadap peneliti sebagai instrumen meliputi validasi terhadap pemahaman metode penelitian kualitatif, penguasaan wawasan terhadap bidang yang diteliti, kesiapan peneliti untuk memasuki objek penelitian, baik secara akademik maupun logistiknya (Gunawan, 2013).

Instrumen utama dalam penelitian kualitatif adalah peneliti sendiri. Namun, selanjutnya setelah fokus penelitian menjadi jelas, maka akan dikembangkan intrumen penelitian sederhana, yang diharapkan dapat melengkapi data dan membandingkan dengan data yang telah ditemukan melalui observasi dan wawancara sedangkan yang melakukan validasi adalah peneliti sendiri (Nugrahani \& Hum, 2014). Penelitian ini dilakukan di SMPU Al-Furqon Driyorejo Gresik mengenai implementasi program tahfidzul Qur'an.

1. Data Primer adalah data yang langsung memberikan data kepada pengumpul data. Antara lain Guru-guru, siswa dan orangtua

2. Data Sekunder adalah data yang tidak langsung memberikan data kepada pengumpul data. Antara lain Buku, jurnal, laporan penelitian dan dokumen dokumen yang menjadi fokuspenelitian (Ahmad \& Radjilun, 2021).

1. Observasi

Observasi (observator) atau pengamatan merupakan suatu teknik atau cara mengumpulkan data dengan jalan mengadakan pengamatan terhadap kegiatan yang sedang berlangsung. Observasi dapat dilakukan secara partisipatif atau nonpartisipatif. Dalam observasi parsipatif (participan observation) pengamatan ikut serta dalam kegiatan yang sedang berlangsung, pengamat ikut sebagai peserta rapat atau peserta penelitian. Dalam observasi nonpartisipatif (nonparticipatory observation) pengamat tidak ikut serta dalam kegiatan, dia hanya berperan mengamati kegiatan, tidak ikut dalam kegiatan (Rikza, 2015)

2. Wawancara

Wawancara (interview) merupakan salah satu bentuk teknik pengumpulan data yang banyak digunakan dalam penelitian deskriptif kualitatif .Wawancara dilaksanakan secara lisan dan tatap muka secara individual, adakalanya juga wawancara dilakukan secara kelompok, kalau memang tujuannya untuk menghimpun data dari kelompok seperti wawancara dengan satu keluarga, pengurus yayasan, pembina pramuka, dll. Wawancara yang diajukan untuk memperoleh data dari individu dilaksakan secara individual (Rikza, 2015).

3. Dokumentasi

Teknik pengumpulan data pada penelitian ini adalah teknik dokumentasi yaitu pengumpulan data dari sumber yang berupa catatan, transkrip, buku, surat kabar, 
majalah, rapat, dan sebagainya yang diperoleh dari sumber primer dan sekunder (Arikunto, 2010).

4. Teknik Analisis Data

Analisis data dalam penelitian kualitatif, dilakukan pada saat pengumpulan data berlangsung, dan setelah selesai pengumpulan data dalam periode tertentu. Pada saat wawancara, peneliti sudah melakukan analisis terhadap jawaban yang di wawancarai. Bila jawaban yang di wawancarai setelah dianalisis terasa belum memuaskan, maka peneliti akan melanjutkan pertanyaan lagi, sampai tahap tertentu, diperoleh data yang dianggap kredibel (Nugrahani \& Hum, 2014).

\section{Hasil dan Pembahasan}

1. Sejarah Berdirinya SMPU Al-Furqon Driyorejo Gresik

Pondok Pesantren Al-Furqon Unggulan berlokasi di perumahan Kota Baru Driyorejo Gresik. Pesantren yang didirikan 3 tahun yang lalu tersebut merupakan wujud ikhtiar KH. Mashuri Abdurrahim dalam rangka membendung daerah yang rawan dengan sarang radikalisme. Pondok tersebut pengembangan dari pesantren AlFurqon Utama yang bertempat di Desa Wedoroanom Driyorejo Gresik. Sebelumnya, perumahan Kota Baru Driyorejo merupakan kawasan perumahan yang cukup padat penduduknya. Disana telah banyak masuk kultur kebudayaan kota yang cukup memerlukan perhatian. Penghuninya rata-rata masyarakat awam yang awalnya hidup di tengah kota kemudian mengalami ruralisasi karena faktor pemenuhan kebutuhan hidup dan pengembangan kota.

Kyai Mashuri menyampaikan bahwa awal mula pendirian pesantren tersebut berawal dari amanah tanah wakaf 2 kavling dari seorang donatur pewakaf. Beliau diamanahkan untuk memanfaatkan tanah tersebut untuk kepentingan keagamaan. Kemudian beliau mengamini untuk memanfaatkan sebagai pesatren Tahfidzul Qur'an. Alhamdulillah, kami mendapatkan amanah tanah wakaf dari seorang pewakaf yang sangat dermawan, beliau adalah Almarhum Bapak Fathul Mujib. Awalnya saya merasa bingung akan memanfaatkan untuk apa. Tapi Alhamdulillah, Allah memberikan jalan untuk mendirikan pesantren di tengah perumahan yang padat penduduk ini terang Kyai Mashuri.

Beliau melanjutkan bahwa keadaan tersebut juga diilhami oleh peristiwa penggrebekan teroris yang ada di kawasan perumahan itu. Diketahui memang ada beberapa kelompok orang-orang radikalis yang tinggal di perumahan tersebut. Kemudian beliau mengambil sikap dengan mendirikan pesantren Al-Furqon di tempat tersebut satu diantaranya untuk menetralisir pengaruh kelompok radikal yang ada.

\section{a. Profil sekolah}

SMP Unggulan Al-Furqon merupakan sekolah swasta yang berada di jalan Granit Kumala 4-5 No 11-13 Kota Baru Driyorejo Gresik, kode pos 61177. Selain itu luas tanah sekolah mencapai $1700 \mathrm{~m} 2$, luas bangunan $1400 \mathrm{~m} 2$ dengan izin operasional 22-12- 2017 s.d.21-12-2020. 
b. Visi Misi Sekolah

1. Visi SMP Unggulan Al-Furqon Driyorejo Gresik

Terwujudnya generasi Qur'ani yang ahli fikir, dzikir, ikhtiar, dan tawakal

2. Misi SMP Unggulan Al-Furqon Driyorejo Gresik

- Mengintegrasikan ilmu kahuniyah, qhauliyah dan amaliyah.

- Meluluskan santri yang berakhlaqul kharimah, berpikir ilmiah dan berkepribadian islami.

- Mendidik generasi hafal Quran yang mandiri.

- Menciptakan iklim pembelajaran yag mendukung penghafalan Al-Quran.

2. Hasil Penelitian Tentang Program Tahfidz Di SMP Unggulan

Gambaran dasar tentang program tahfidz yaitu penggabungan sistem pembelajaran formal (kurikulum 13/sistem klasik) dengan sistem pembelajaran pondok pesantren (sistem talaqi).

a. Sistem Klasik

Pelaksanaan sistem klasik yakni dengan 6 kali pertemuan selama satu minggu. Santri mengikuti proses pembelajaran dimulai pukul $07.30-14.05$ WIB dengan menggunakan kurikulum yang telah dirancang oleh dinas pendidikan dengan menggunakan kurikulum K13. Materi yang diajarkan dalam kurikulum tersebut adalah materi pelajaran umum dan materi diniyah pondok.

b. Sistem Talaq (cara belajar mengajar Al-Qur'an)

Pelaksanaan pembelajaran tahfidz Qur'an para siswa dibagi kedalam beberapa halaqoh-halaqoh tahfidz. Tiap halaqoh beranggotakan 5-10 anak dan didampingi oleh satu pembimbing, materi yang disampaikan dalam halaqah tersebut adalah ziadah dan murajaah.

- Ziadah

Merupakan kegiatan menghafalkan Al-Quran dan menyetorkan hafalan baru yang dilaksanakan sebelum matahari terbit.

- Murojaah

Merupakan kegiatan mengulang hafalan yang di miliki agar tidak hilang (Tresnawati \& Wijaya, 2016).

Hal ini sesuai dengan apa yang dikatakan oleh Bapak Toyyibin, S.Pd selaku waka kurikulum SMP Unggulan Al- Furqon Driyorejo Gresik. Beliau mengatakan bahwa metode tahfidz Al-Qur'an yang digunakan sudah bagus, dibuktikan dalam lulusan pertama kita sudah mendapatkan 5 santri yang hafal 7 juz dalam waktu 3 tahun dengan jumlah siswa 10, tetapi kita butuh evaluasi yang banyak karena kita sekolah baru yang usianya 3 tahun berjalan, dan disekitar Kecamatan Driyorejo belum ada sekolah berbasis tahfidz baru SMP Unggulan Al-Furqon lah sekolah pertama yang ada di kecamatan Driyorejo. Saya yakin kedepannya SMP Unggulan Al-Furqon menjadi sekolah junjungan orang untuk di rekomendasikan ke khalayak karena program tahfidz nya.

Kurikulum tahfidz Qur'an dirancang secara mandiri oleh seluruh pimpinan dan stake holder yang ada di SMP Ungulan Al- Furqon. Target yang di fokuskan 
dalam kurikulum tersebut adalah santri selama 3 tahun mampu menghafal dan memahami makna dalam kandungan ayat suci Al-Qur'an.

Kebijakan kurikulum tahfidz Qur'an secara umum sebagai berikut:

a. Landasan Penyusunan Kurikulum

1. Tahfidz merupakan mata pelajaran istimewa.

2. Materi penunjang dalam pogram tahfidz antara lain: Tajwid, Tasmi, Tafsir dan darurah Al- Qur'an.

3. Target yang dicanangkan dalam program tersebut adalah 15 juz selama 3 tahun.

4. Nilai Al-Qur'an sebagai ruh keagamaan pada santri.

b. Teknis Pencapaian Target

1. Para santri dibagi kedalam kelompok-kelompok halaqoh.

2. Perbandingan antara pengajar dan santri adalah 1:20.

3. Pengajar tahfidz dibawah koordinasi mas'ul al tahfidz.

4. Mas'ul al tahfidz adalah grand hafidz yang matqon fiitilawah.

5. Waktu pelaksanan tahfidz dilaksanakan dalam tiga waktu antara lain: ba'da subuh, ashar, dan isya'.

6. Ujian tahfidz di pimpin master tahfidz.

c. Marhalah Tahfidz

Mendapatkan julukan sebagai Hafidz Qur'an tidaklah mudah, mereka harus dinyatakan lulus dengan memenuhi beberapa kompetensi dasar yang dikenal dengan marhalah tahfidz. Ada dua marhalah yang harus dilalui para santri untuk dinyatakan lulus, yakni:

1. Marhalah tahsin (bimbingan membaca Al-Qur'an) marhalah ini dilaksanakan oleh semua santri dengan kompetensi membaca Al-Qur'an secara tartil baik fashohah maupun tajwidnya.

Beberapa tahsin yang harus di miliki santri antara lain:

a) Tahsin makhroj

b) Tahsin nun mati dan mim

c) Tahsin mad

d) Tahsin ghrib

e) Tahsin Tahfidz

Setelah santri dinyatakan lulus marhalah tahsin. Ada beberapa yang harus dijadikan pedoman dalam pencapaian marhalah yakni:

1. Marhalah tahsin diselesaikan maksimal 4 bulan

2. Sebelum tahsin selesai, santri tidak boleh masuk marhalah tahfidz

Hal ini diungkapkan oleh Faizal Zaelani guru penanggung jawab program tahfidz di SMP Unggulan Al-Furqon Driyorejo Gresik bahwa:

"Adanya program tahfidz di SMP Unggulan Al- Furqon ini sangat jarang ada di sekolah-sekolah sekitar Driyorejo ini, maka dari itu insyaAllah sekolah ini akan berkembang pesat dan mencetak generasi Qur'ani. Secara metode di SMP Unggulan ini sama seperti metode yang ada di Pondok Kudus (Kyai Arwani) yaitu 
dibagi menjadi beberapa bagian (Marhalah) seperti: Juz 1-5 di kelompok 1 dan Juz 6-10 dikelompok 2 begitu seterusnya, karena kalau dibagi menjadi beberapa marhalah itu, guru akan lebih fokus dan teliti dengan hafalan nya siswa-siswa dan lebih tepat dan untuk tahsin dibagi menjadi 3 kelompok, yaitu:

1. Ula lebih fokus di makhroj dan sifat huruf

2. Wustho lebih fokus di di tajwid dan gharibulqiraah

3. Ulya lebih fokus di melancarkan dan mengkhatamkan hafalan (Mualif, 2020).

Hal tersebut juga dibenarkan oleh Bapak Mualif, S.Pd selaku kepala sekolah SMP Unggulan Al-Furqon Driyorejo Gresik bahwa:

"SMP Unggulan Al-Furqon ini baru berusia 3 tahun ini, dan baru mengeluarkan lulusan pertama tahun ini dengan jumlah 10 siswa, dan alhamdulillah pada lulusan pertama ini kita sudah bisa melakukan wisuda Qur'an yang pertama juga dengan 5 siswa hafalan terbanyak yaitu ada yang 5, 6, dan 7 juz. Kalau mengenai metode tahfidz yang ada di SMP Unggulan, kita sudah membuatkan kurikulum program tahfidz seperti yang sudah dicantumkan oleh penulis dengan teknisi memperbanyak jam pada program tahfidz, kalau sekolah formal lainnya pulang pada pukul 12.00, tetapi di SMP Unggulan ini pulangnya 14.30 (Mualif, 2020).

3. Faktor Pendukung Dalam Program Tahfidz di SMP Unggulan Al- Furqon Driyorejo Gresik

Dari hasil penelitian dengan penanggung jawab program tahfidz SMP Unggulan Al-Furqon bahwa setiap metode pembelajaran memiliki plus dan minus, kelebihan maupun kekurangan. Begitupun dengan metode tahfidz yang ada di SMP Unggulan Al-Furqon. Oleh karena itu, pengajar harus selektif dalam melaksanakan metode pembelajaran dan disesuaikan kemampuan santri. Karena metode pembelajaran yang diterapkan akan berpengaruh pada hasil hafalan siswa.

Faktor pendukung keberhasilan guru dalam menerapkan metode tahfidz pada siswa SMP Unggulan Al-Furqon, yaitu dengan empat cara, yaitu:

a. Guru memulai kegitan awal

1. Guru mengucapkan salam dilanjutkan dengan berdo'a saat memulai aktivitas.

2. Guru memberikan apresiasi berupa pertanyaan mengenai hafalan.

3. Guru memotivasi siswa untuk bersemangat mengikuti hafalan. Dengan bercerita tentang keutamaan seorang penghafal, pahala orang menghafal dan dosa apabila lupa dengan hafalannya.

4. Guru melakukan kegiatan inti, yaitua:
a. Siswa menyetorkan hafalannya
b. Guru memberikan materi tajwid
c. Siswa diberi tugas untuk mencari contoh bacaan tajwid di Al-Qur'an

5. Guru mengakhiri kegiatan sebagai berikut:

a. Siswa diminta menjawab pertanyaan yang diberikan guru

b. Guru mengakhiri pembelajaran dengan mengucapkan syukur, do'a penutup majelis dan salam penutup 
c. Guru memberikan penilaian pada siswa tahfidz

Penilaian yang digunakan dalam pembelajaran tahfidz di SMP Unggulan AlFurqon adalah ujian tahfidz, dengan teknisi guru memberikan pertanyaan tentang sambung ayat, tebak surat, dan tajwid, dari sebuah penilaian itulah jika terjadi sesuatu nilai yang kurang diharapkan maka akan diadakan evaluasi untuk mencari solusi dalam meningkatkan hafalan siswa SMP Unggulan Al-Furqon (Penelitian, 2020).

4. Faktor penghambat Dalam Program Tahfidz di SMP Unggulan Al- Furqon Driyorejo Gresik

Dari hasil pengamatan di lapangan dan wawancara, peneliti menemukan sebuah faktor penghambat dari metode tahfidz yang ada di SMP Unggulan AlFurqon yakni kebanyakan yang berhasil memenuhi target dari program tahfidz yaitu anak laki-laki yang bermukim dipesantren, akan tetapi anak yang tidak mukim dipesantren laki-laki maupun perempuan sangat sulit sekali untuk mencapai target yang ditentukan maka dari itu, menurut peneliti bahwa pengawasan orang tua dan support dari orang tua lah yang utama karena kurangnya tenaga pengajar tahfidz yang dimiliki SMP Unggulan.

\section{Kesimpulan}

Dari penelitian yang telah diuraikan di atas dengan judul " Pengaruh Penggunaan Media Pembelajaran dan Kreativitas Guru terhadap Minat Belajar Siswa SMP Unggulan Al-Furqon Driyorejo Gresik", dalam pembelajaran tahfidz siswa Al-Furqon dilibatkan langsung dalam kegiatan pembelajaran yang menarik, efektif, dan efisien dengan menggunakan beragam cara dari mulai pembelajaran tajwid beserta cara mencari bacaan tajwidnya, hafalan beserta lagu-lagu yang diajarkan atau dengan metode murojjaah nya, sehingga hafalan dan materi tajwid yang didapatkan dapat lebih mudah difahami dan diingat tanpa mudah dilupakan, sehingga metode tahfidz ini mampu meningkatkan daya ingat siswa dalam menghafal Al-Qur'an yang sedang dihafal dan yang sudah dihafal, siswa lebih kreatif dalam memanfaatkan suaranya dengan cara menghafal menggunakan berbagai macam lagu yang sesuai dengan ayat yang terkandung di Al-Qur'an bisa juga dengan tartil atau qiroah. Didalam keberhasilan seorang siswa tidak lepas dari kerja keras seorang guru untuk terwujudnya pembelajaran yang menyenangkan dan tidak membuat siswa stres dalam menghafal, tentu di perlukan ide-ide kreatif dan inovatif guru dalam merancang strategi pembelajaran yang menyenangkan, dengan merancang strategi yang menyenangkan. 


\section{BIBLIOGRAFI}

Ahmad, R., \& Radjilun, M. S. (2021). Biografi Sultan Baabullah Datu Syah (Studi; Tentang Pewarisan Nilai-Nilai Karakter Sebagai Sumber Belajar Sejarah Di Sma Dalam Kurikulum 2013). Sandhyakala Jurnal Pendidikan Sejarah, Sosial Dan Budaya, 2(1), 1-14. Google Scholar

Arikunto, S. (2010). Prosedur Penelitian Suatu Pendekatan Praktik, Jakarta: Rineka Cipta, Cet. Ke-13. Google Scholar

Depiyanti, O. M. (2014). Model Pendidikan Karakter Di Islamic Full Day School (Studi Deskriptif Pada Sd Cendekia Leadership School, Bandung). Tarbawy: Indonesian Journal Of Islamic Education, 1(2), 132-141. Google Scholar

Gunawan, I. (2013). Metode Penelitian Kualitatif. Jakarta: Bumi Aksara, 143. Goolge Scholar

Idhan, I., Kahar, F., \& Yamin, M. N. (2019). Implementasi Kebijakan Pendidikan Baca Tulis Al-Qur'an (Studi Kasus Taman Pendidikan Al-Qur'an Di Kecamatan Tamalanrea Kota Makassar). Universitas Negeri Makassar. Google Scholar

Mu'ammar, M. N. (2019). Study Of Approaches, Methods, Sources And Interpretation Instruments Of Mulla Sadra. International Journal Of Islamic Khazanah, 9(1), 18. Google Scholar

Mualif. (2020). Wawancara. Google Scholar

Mudzakir, A. S. (2013). Studi Ilmu-Ilmu Quran. Bogor: Pustaka Litera Antar Nusa. Google Scholar

Nugrahani, F., \& Hum, M. (2014). Metode Penelitian Kualitatif. Solo: Cakra Books. Google Scholar

Paridi, A. (2019). Implementasi Program Pengembangan Karakter Islami Melalui Program Tahfidz. Khazanah Pendidikan Islam, 1(1), 12-21. Google Scholar

Penelitian, O. (2020). Observasi Penelitian. Google Scholar

Rajak, P. F. (2017). Implementasi Program Tahfidz Al-Qur'an Juz 29 Di Madrasah Tsanawiyah Negeri 2 Ciganjur Jakarta Selatan. Perpustakaan Ilmu Tarbiyah Dan Keguruan. Google Scholar

Rikza, M. R. (2015). 


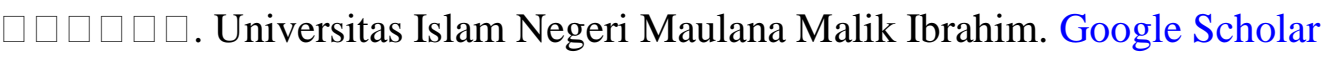

Subandi, L. C., \& Chairani, L. (2010). Psikologi Santri Penghafal Al-Qur'an. Yogyakarta: Pustaka Pelajar. Google Scholar

Tresnawati, D., \& Wijaya, C. (2016). Rancang Bangun Media Interaktif Muroja'ah Matan Jurumiyyah Berbasis Android. Jurnal Algoritma, 13(2), 414-419. Google Scholar

\section{Copyright holder :}

Umi Intiha'ul Habibah (2021)

First publication right :

Journal Syntax Admiration

This article is licensed under:

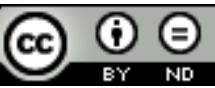

